\title{
Additively Manufactured Ti-6Al4V before and after Hot Isostatic Pressing
}

\author{
Brad Baker, Keegan Wisdom* \\ Mechanical Engineering Department, Unites States Naval Academy, Annapolis, MD, USA \\ Email: bbaker@usna.edum, *wisdom@usna.edu
}

How to cite this paper: Baker, B. and Wisdom, K. (2021) Additively Manufactured Ti6Al4V before and after Hot Isostatic Pressing. World Journal of Engineering and Technology, 9, 268-284.

https://doi.org/10.4236/wjet.2021.92019

Received: May 20, 2020

Accepted: May 5, 2021

Published: May 8, 2021

Copyright (อ 2021 by author(s) and Scientific Research Publishing Inc. This work is licensed under the Creative Commons Attribution International License (CC BY 4.0).

http://creativecommons.org/licenses/by/4.0/ (c) (i) Open Access

\begin{abstract}
The crystalline structure and mechanical properties of titanium $6 \mathrm{Al} 4 \mathrm{~V}$ produced via selective laser sintering were compared to literature examples and to wrought samples. In total, three sets of samples were analyzed: wrought, as printed selective laser sintering samples with no post processing, and selective laser sintering samples that were further processed via hot isostatic pressing for final consolidation. Samples were sectioned to fit on graphitic resin pucks and cut from the build plane in two orthogonal planes. Images were taken using a TESCAN MIRA3 scanning electron microscope with electron backscatter diffraction analysis and samples were etched for optical analysis. Hardness of the samples was measured using a Vickers hardness indenter. The overall chemical composition of the samples, both AM and wrought, were similar as confirmed using energy dispersive spectroscopy. Beta grains were observed in a columnar orientation along the build direction, however, the grain orientation did not appear to affect the hardness of the sample. A small amount of grain growth was observed in the post processed samples as compared to the as printed samples.
\end{abstract}

\section{Keywords}

Additive Manufacturing, Selective Laser Sintering, Titanium Alloys, Electron Backscatter Diffraction

\section{Introduction}

Today's world of complex machinery coupled with increased costs presents new manufacturing challenges. Traditional methods of manufacture generally require costly and time-consuming finishing processes before the final part is ready for use. Additive Manufacturing (AM) seeks to solve this problem by being able to quickly and cost effectively produce parts that require little, if any, machining in 
post-production. However, the ability to design and create complex forms with little waste does not come without concern for quality control [1]. The positives of AM are great enough that both individuals and industry are leading the charge to create those quality control measures and discover new methods of production [2]. This research is focused on a comparison of samples of titanium alloy (Ti64) created using an AM technique known as selective laser sintering (SLS). The combination of AM and Ti64 is popular due to the high demand in industry for the alloy and the cost associated with traditional manufacturing methods [3].

AM was developed in the 1980 's, initially as a way to quickly create models and prototype parts as new technologies such as computer aided design (CAD), computer aided manufacturing (CAM), and computer numerical control (CNC) came into the market. 3D printing or rapid prototyping are often used interchangeably with AM, however, they are both subsets of AM. Utilizing CAD software or 3D scans of parts to create solids, the information is converted to a stereolithography (STL) file that approximates the object as a series of triangles and slices that will form each layer being produced [4]. Since the process only adds the material that is required for final use, post processing is reduced. This process also allows the creation of complex and hollow shapes that can maintain strength while reducing materials and allows the use of engineered materials with complex gradients, properties, and microstructures that would be expensive or even impossible to produce using traditional methods [4] [5]. This potentially saves time, money, materials and weight. These features are highly desirable in the manufacturing sector.

AM is not just a single method of production, but a term to describe a process in which material is added layer by layer vice subtracted in order to create a new part. There are liquid, solid, and powder based methods each using some form of melting, polymerization, lamination, or binding to create a solid object from the base material. AM can be described by seven process categories: vat photo-polymerization, material extrusion, material jetting, binder jetting, sheet lamination, directed energy deposition and powder bed fusion. Table 1 summarizes these categories based on the base material used, how the material is bonded, and the feedstock method used to deposit the material [6].

The most common AM methods are polymer based and include vat photopolymerization, material extrusion, material jetting, binder jetting, and sheet lamination. Vat photopolymerization is a liquid polymer process that is among the oldest methods of AM and is also one of the most widely used. Patented in 1986 to the process uses an ultraviolet laser as a catalyst to solidify a base material of photopolymer resin. The resin is placed on a platform, as the laser solidifies specific locations on the platform, the platform is lowered to make the next layer [4]. While traditionally used with a liquid feedstock, powered material can also be used. For this method, the base material is dispersed throughout a UV curable resin in powder form along with photoactive components [7]. Material extrusion is one of the more common AM techniques for most consumer applications. 
Table 1. Summary of AM processes.

\begin{tabular}{|c|c|c|c|c|c|c|c|}
\hline & $\begin{array}{l}\text { Material } \\
\text { Extrusion }\end{array}$ & $\begin{array}{c}\text { Material } \\
\text { Jetting }\end{array}$ & $\begin{array}{l}\text { Powder } \\
\text { Bed } \\
\text { Fusion }\end{array}$ & $\begin{array}{c}\text { Directed } \\
\text { Energy } \\
\text { Deposition }\end{array}$ & $\begin{array}{l}\text { Binder } \\
\text { Jetting }\end{array}$ & $\begin{array}{c}\text { Vat } \\
\text { Photo- } \\
\text { Polymerization }\end{array}$ & $\begin{array}{c}\text { Sheet } \\
\text { Lamination }\end{array}$ \\
\hline \multicolumn{8}{|l|}{ Material } \\
\hline Metal & & & $\mathrm{X}$ & $\mathrm{X}$ & $\mathrm{X}$ & $\mathrm{X}$ & $\mathrm{X}$ \\
\hline Ceramic & & & $\mathrm{X}$ & & $\mathrm{X}$ & $\mathrm{X}$ & $\mathrm{X}$ \\
\hline Polymer & $\mathrm{X}$ & $\mathrm{X}$ & $\mathrm{X}$ & & $\mathrm{X}$ & $\mathrm{X}$ & $\mathrm{X}$ \\
\hline Composite & & & $\mathrm{X}$ & & $\mathrm{X}$ & $\mathrm{X}$ & $\mathrm{X}$ \\
\hline \multicolumn{8}{|l|}{ State of fusion } \\
\hline $\begin{array}{l}\text { Thermal } \\
\text { reaction bonding }\end{array}$ & $\mathrm{X}$ & $\mathrm{X}$ & $\mathrm{X}$ & $\mathrm{X}$ & $\mathrm{X}$ & & $\mathrm{X}$ \\
\hline $\begin{array}{l}\text { Chemical } \\
\text { reaction bonding }\end{array}$ & & $\mathrm{X}$ & & & $\mathrm{X}$ & $\mathrm{X}$ & $\mathrm{X}$ \\
\hline \multicolumn{8}{|l|}{ Feedstock } \\
\hline Filament/wire & $\mathrm{X}$ & & & $\mathrm{X}$ & & & \\
\hline Powder & & & $\mathrm{X}$ & $\mathrm{X}$ & $\mathrm{X}$ & $\mathrm{X}$ & \\
\hline Sheet stack & & & & & & & $\mathrm{X}$ \\
\hline Liquid & & & $\mathrm{X}$ & & $\mathrm{X}$ & $\mathrm{X}$ & \\
\hline Thermoplastic & & & $\mathrm{X}$ & & $\mathrm{X}$ & & \\
\hline Melted Material & & $\mathrm{X}$ & & & & & \\
\hline
\end{tabular}

More commonly known as fused deposition modeling (FDM), this method uses a nozzle that feeds a polymer filament to a build plate. As the filament is fed through the nozzle, it is thermally bonded and extruded into the desired layer [4]. FDM parts are generally covered with ridges due to the size of the nozzle creating the part. Further processing of the part to achieve the desired surface texture is done either chemically or mechanically [8]. Material jetting is a process in which droplets of the build material are selectively placed on the build platform and then cured by UV light [6]. Inkjet 3D printers use a piezo printing head to deposit multiple photopolymer resins on a moveable platform in order to create parts that are made of more than one material. This method has been increasing in usage and popularity due to the ability to create functional components as well as prototypes [9]. Binder jetting was developed by the Massachusetts Institute of Technology in 1993 and was commercialized in 2010 [10]. Similar to other AM processes, binder jetting builds the sample a layer at a time. The system places a layer of power on to a movable bed, and then a binding agent is selectively jetted onto the powder bed via a jet. As a layer is completed, the powder bed is moved, another layer of powder is laid down and the process repeats until the desired part is complete. Once the part is complete, the unbounded powder is removed and has some ability to be reused. Rather than polymer based powders used in other processes, binder jetting has the ability to use 
sand, glass, metal, calcium carbonate, acrylic, and ceramic powders [10]. The sheet laminating process is also known as laminated object modelling. Rather than powder beds or polymer resins, this method layers thin laminates that are glued together and then cut to shape. Objects are built up layer by layer from these solid laminates and then must be cut or machined into their final shapes. Generally, the feedstock material defines layer resolution. Two distinct methods for sheet laminating exist; the traditional method and computer-aided manufacturing of laminated engineering materials [7]. The traditional method for this process involves a working material that is embedded into tape layers. The layers are stacked and then cut to form the outline of the part. A roller presses and heats the tape to activate the adhesive. The tape portion is then removed via de-binding and sintering in a furnace, leaving behind the working material. The final part may be further machined from this stock. For this method, the layers are precut before they are stacked for lamination. This allows for more complex shapes and internal voids to be created more easily.

The more complex and capable metal based AM methods include Directed Energy Deposition (DED) and Powder Bed Fusion (PBF). DED uses an energy source, typically a laser or electron beam, to melt a feedstock material to produce the final shape. The feedstock can either be fed by spreading a layer of powder or by directing the material through a nozzle to the melt pool [11]. PBF places thin layers of powder on a build plane and selectively focuses an energy source to fuse the powder at specific locations in order to produce the desired shape [12]. As each layer is completed, a new layer is placed and the process is repeated until the final part is complete. The main difference between DED and PBF is in the distribution of the bulk material. DED uses a nozzle to position the feedstock for fusion and PBF uses the powder bed itself [6]. SLS and Selective Laser Melting (SLM) are both subsets of the BPF process, and SLS specifically is the process that created the sample material for this analysis. Particles are spread out on a movable bed that is lowered to build up more layers as a laser fuses the particles in a predetermined pattern [4]. While the exact method to produce the samples analyzed is proprietary information and is not available, the basic process followed traditional SLS AM methodology. Due to the use of powder-based feedstock and the high-localized temperatures associated, SLS can be used to manufacture parts from hard materials or materials with high melting points [13].

The layered natured of AM parts creates a concern for the possibility of the formation of structural defects in the produced part. Possible defects are caused by poor manufacturing practices and include agglomeration of powders, stress cracking, excess porosity, and improper fusion of feedstock, which can all affect the mechanical properties of the completed part [14]. Although the original patents for AM were filed over 35 years ago, these potential defects have prevented widespread adoption of their use [12]. Tighter controls on build parameters and post processing can help to reduce or eliminate those defects and recent studies have shown that AM samples can demonstrate properties with similar to or bet- 
ter than the wrought material [15] [16]. As previously stated, the samples used in this study were made using SLS. The concern is that pores could be created during the layering and packing of the powdered metal working material and cause undesirable mechanical properties. In an effort to removal the pores, samples were processed using HIP. In simple terms, the HIP process involves placing the part into a chamber filled with an inert gas. Heat is applied (hot) in order to raise the pressure of the vessel and the resulting pressure (pressing) of the gas is applied to all surfaces uniformly (isostatic). The heat and pressure applied is of critical importance and varies between materials. The temperature used is necessary to reduce the yield strength and raise the diffusivity of the working material in order to allow the pores to close properly. However, if the temperature is too high, unacceptable levels of grain growth could occur resulting in changes in microstructure and resultant material properties. The pressure works to ensure the solubility of any gasses released due to collapsing pores. If the pressure were too low, some gases would escape to another pore vice the surface [17]. This combination of temperature and pressure can allow engineers to produce parts with specific material properties. Along with demonstrating the properties of the samples, this research aims to determine if HIP is required for this particular application.

Pure titanium consists of a hexagonal close packed (HCP) structure at room temperature, known as the alpha $(\alpha)$ phase. A phase transformation to a body centered cubic (BCC) structure occurs at high temperatures $\left(980^{\circ} \mathrm{C}\right.$ for Ti-64), known as the beta $(\beta)$ phase [18]. These grain structures are shown in Figure 1. By alloying pure titanium with other metals, manufactures can create alloys with $\alpha$, $\beta$, or $\alpha+\beta$ structures in order to obtain desired properties. Alloys of $\alpha$ structure tend to have greater weld-ability and higher resistance to creep while still maintaining a satisfactory level of strength and toughness. Alloys of $\beta$ structure tend to have improved formability and good ductility. Alloys of $\alpha+\beta$ structure can be treated to control the amount of $\alpha$ or $\beta$ present to create the desired properties [19]. In general, $\alpha$ phase titanium has a relatively low hardness when compared to $\beta$ phase titanium. This is due to grain size and the presence of martensite acicular structures [20]. As heat treatment is applied to an $\alpha$ phase sample, the grain size increases. This cause a reduction in the boundary area and
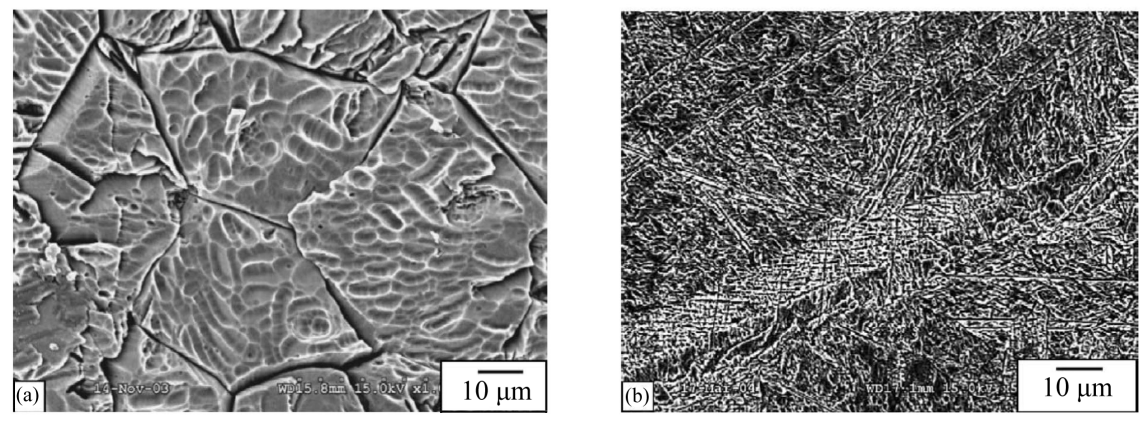

Figure 1. Micrographs of (a) $\alpha$-Ti and (b) $\beta$-Ti specimens [20]. 
results in a lower hardness value. Therefore, smaller grains yield a harder sample. $\beta$ phase samples undergo the same grain size change during heat treatment; however, we see the opposite effect in hardness. The driving factor is the presence of needle-like martensitic acicular structures. As grain size increases, so does the width of the martensite and as a result, the hardness increases.

Titanium alloys are used in a wide range of fields. The medical industry heavily uses alloys for replacement body parts such as hip joints and knees due to the biocompatibility of the alloy with the human body. This is due in part to the presence of a passive oxide layer that forms over the surface that is retained at the $\mathrm{pH}$ values found in the human body [21]. Chemical and marine industries use the material due to the resistance to corrosion. The aerospace industry is one of the largest users of titanium alloys due to the high strength to weight ratio and its ability to withstand high temperature. Ti 64 is the most commonly used alloy in the industry. It is an $\alpha+\beta$ alloy consisting of $6 \%$ of aluminum to stabilize the $\alpha$ phase and $4 \%$ of vanadium to stabilize the $\beta$ phase [19]. Nominal chemistry requirements of Ti64 are shown in Table 2. The alloy is also popular due to the ability to heat treat it in order to obtain the desired strength to weight ratio for the application.

The properties that make Ti64 ideal also contribute to the manufacturing cost, making it prohibitive for many applications. Difficulty cutting, machining, melting, and shaping the material leads to high manufacturing costs. AM aims to solve this problem by providing the ability to make complex shapes that require little to no postproduction machining. It would also reduce waste of raw materials, which would further drive down costs. AM would also allow parts to be recreated remotely, reducing repair time for critical equipment. As previously discussed, there are concerns about the porosity of AM Ti64. For this research, we will compare Ti64 produced via SLS to wrought material from the same manufacturer. We will also determine if HIP changes the hardness of the sample enough to justify the extra processing step.

In this research, analysis is conducted on additively manufactured Ti64 with the intent of determining the impact of post processing on Ti64, characterizing

Table 2. Nominal constituents of Ti64.

\begin{tabular}{cc}
\hline Titanium & Balance \\
\hline Aluminum & $5.50 \%$ to $6.75 \%$ \\
Vanadium & $3.50 \%$ to $4.50 \%$ \\
Iron (maximum) & $0.40 \%$ \\
Oxygen (maximum) & $0.2 \%$ \\
Carbon (maximum & $0.08 \%$ \\
Nitrogen (maximum) & $0.05 \%$ \\
Hydrogen (maximum) & $0.125 \%$ \\
Yttrium (maximum) & $0.005 \%$ \\
\hline
\end{tabular}


the microstructure and hardness of additively manufactured Ti64, and comparing additively manufactured Ti64 to stock Ti64. This research aims to show the difference in grain structure between the planes of AM Ti64 and to make comparisons to traditionally manufactured Ti64.

\section{Experimental Procedure}

Samples of AM Ti-64 were provided by Penn State University. Printing parameters were similar and standard enough to allow comparison with the only significant difference being post processing of the samples. This includes the build process as well as the exact heat treatment processing. Half of the samples were heat treated via HIP. In general, the HIP was conducted by raising the temperature of the sample well beyond the $\beta$ phase temperature $\left(995^{\circ} \mathrm{C} \pm 20^{\circ} \mathrm{C}\right)$ for extended periods of time (Pederson 2002). AM samples were cut in three planes corresponding to standard cartesian planes and then compared to wrought samples of Ti64.

The samples were sectioned to fit in 1.25 inch circular, graphitic resin pucks in the three, orthogonal planes, XY (build plane), YZ, and XZ (orthogonal planes). A TESCAN MIRA3 scanning electron microscope (SEM), operating at $20 \mathrm{KeV}$ and beam current approximately 1 nanoamp for imaging and 4-6 nanoamps for electron backscatter diffraction (EBSD) was used for analysis. EBSD analysis was conducted at a $70^{\circ}$ tilt using an EDAX Hikari camera and OIM analysis software. Optical samples were etched with Krolls reagent and imaged using a Zeiss AxioImager2. For hardness testing, samples were indented using a Wilson Tukon 1202 Vickers hardness tester. Samples were indented at $1 \mathrm{kgf}$ for 15 seconds using a $3 \times 3$ array of indentations as shown in Figure 2. Each indentation was spaced between 3 and 5 times the $\mathrm{d} 1$ measurement of the first indent. The dimensions $\mathrm{d} 1$ and $\mathrm{d} 2$ are used to determine the area of the indentation. When coupled with the known force, a hardness value can be assigned based on the result. For purposes of this analysis, hardness is assumed to be related to strength. Comparing hardness values of the samples will allow comparison between geometries, post build treatments, and previously established construction methods.

\section{Results}

Energy dispersive spectroscopy (EDS) data in Figure 3 and Figure 4 confirm no
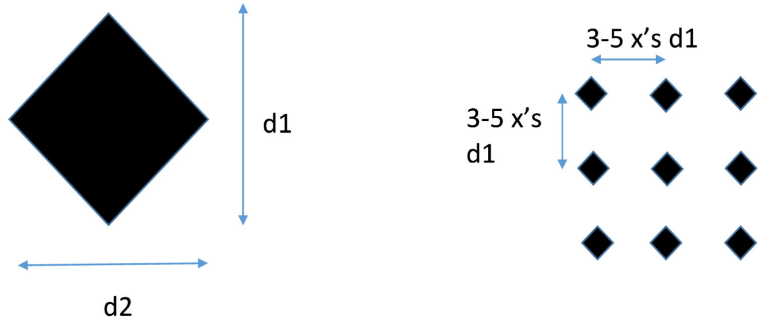

Figure $2.3 \times 3$ indentation grid for hardness testing. 


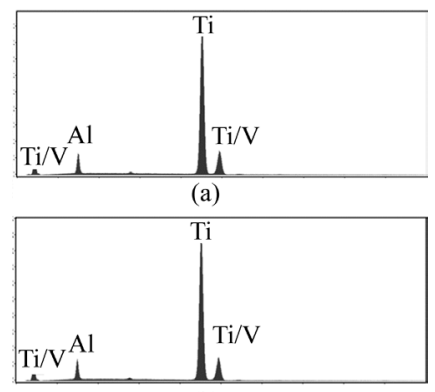

(b)

Figure 3. A comparison of EDS data for (a) non-HIP XY and (b) non-HIP XZ.

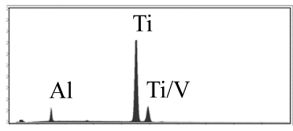

(a)

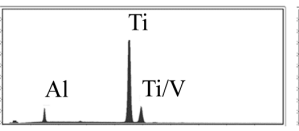

(b)

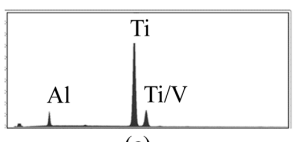

(c)

Figure 4. A comparison of EDS data for (a) HIP (b) non-HIP and (c) wrought samples.

change in the compositional changes in the sample due to post processing by HIP. The samples were compared across all planes, HIP, non-HIP, and SLS versus wrought. All samples were determined to have the same composition of Ti64. This is an expected result and validates that comparing the samples across geometries, treatments, and manufacturing processes will produce results that are caused by those factors. There are no compositional differences between build and orthogonal planes.

Optical images in Figures 5-10 show a difference in grain orientation depending on the plane in which the sample was cut. EBSD images are shown in Figure 11 and Figure 12. EBSD images highlight the contrast between phases and aide in the identification of phase boundaries and grain orientation [22]. As expected, the grains are oriented in the vertical $\mathrm{Z}$ direction (XY plane) in accordance with the SLS build process. As clearly shown, build direction does have a distinct effect on grain orientation. Images of samples in the build plane (BP) show a "top down" view while orthogonal plane (OP) show a more columnar view. These columnar $\beta$ grains are consistent with PBF AM Ti64 [23]. The samples are also clear of visible voids. While pores are commonly associated with SLS according to the literature, the AM method used for these samples did not produce any viable voids and indicates that our samples will be consistent with performance standards for AM Ti-64 [23] [24]. Although the grain orientation changes between planes, Figure 13 and Figure 14 SEM images show a common microstructure between the BP and the OP and further confirm a lack of visible voids. Coupled with the EDS, optical, SEM, and EBSD data, the rest of this analysis will assume that the OPs are virtually identical.

As previously discussed, each sample was evaluated for Vickers hardness using a 3 by 3 grid show in Figure 2. Compiled results are in Table 3. As expected, the heat-treated samples experience a reduction in hardness between $5 \%$ and $7 \%$ across build geometries. The heat treated samples are within $4 \%$ of each other and the non-heat treated values are within $2 \%$. This indicates that build geometry 


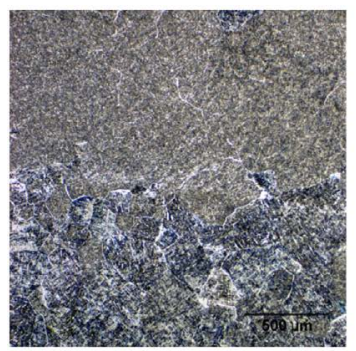

(a)

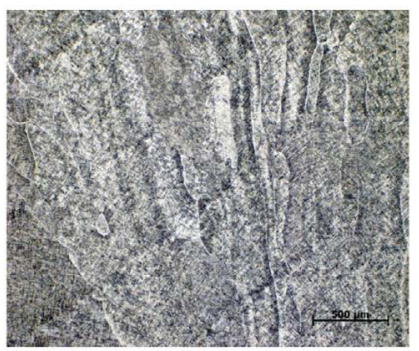

(b)

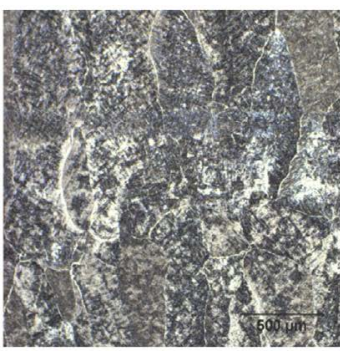

(c)

Figure 5. Comparison of optical data for HIP sample at 50× in the (a) XY, (b) XZ, and (c) YZ planes.

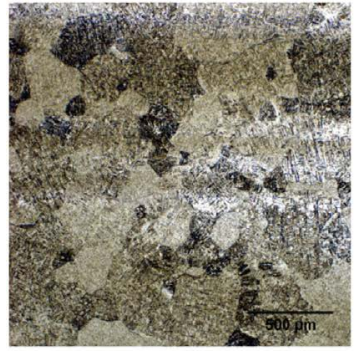

(a)

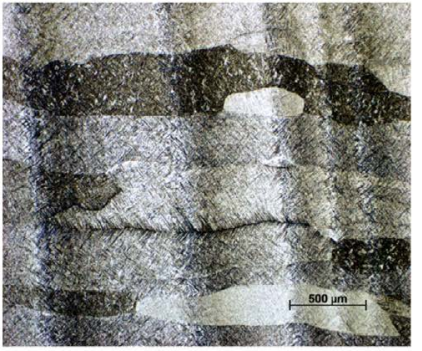

(b)

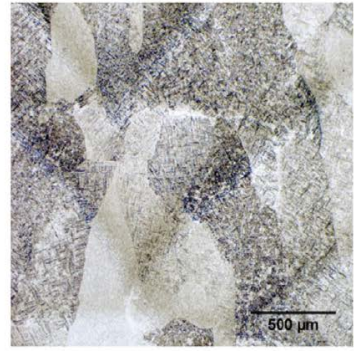

(c)

Figure 6. Comparison of optical data for non-HIP sample at $50 \times$ in the (a) XY, (b) XZ, and (c) YZ planes.

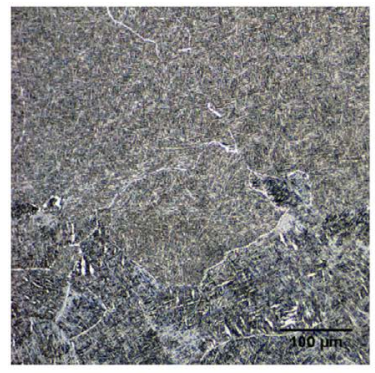

(a)

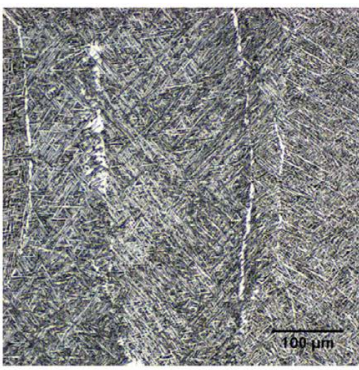

(b)

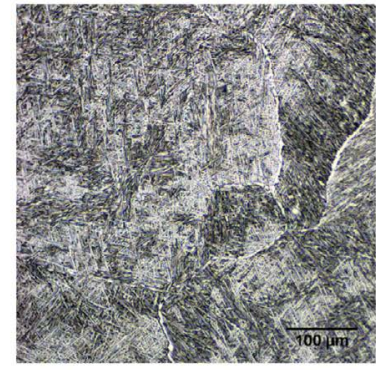

(c)

Figure 7. Comparison of optical data for HIP sample at $200 \times$ in the (a) XY, (b) XZ, and (c) YZ planes.

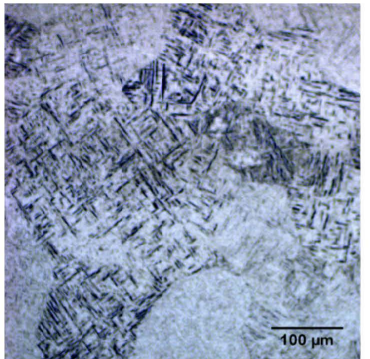

(a)

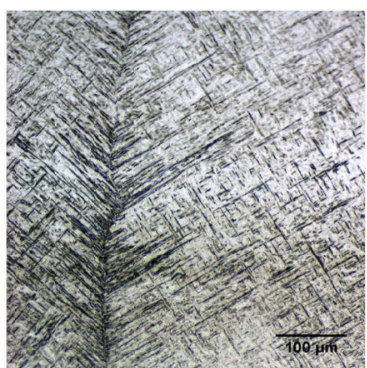

(b)

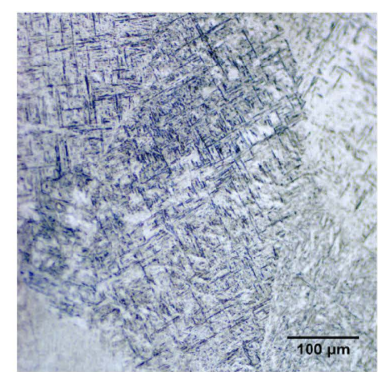

(c)

Figure 8. Comparison of optical non-data for non-HIP sample at $200 \times$ in the (a) XY, (b) $\mathrm{XZ}$, and (c) YZ planes. 


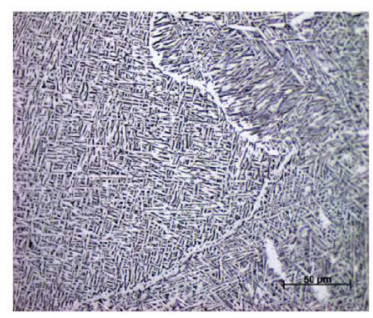

(a)

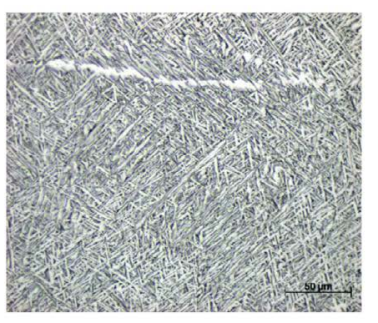

(b)

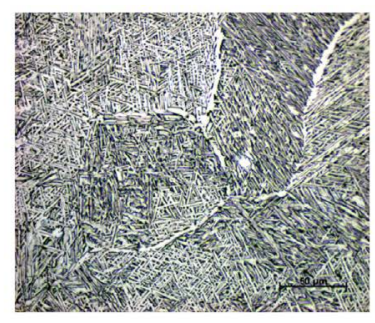

(c)

Figure 9. Comparison of optical data for HIP sample at 500× in the (a) XY, (b) XZ, and (c) YZ planes.

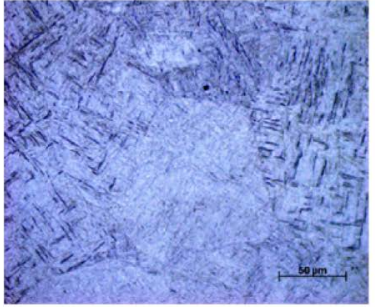

(a)

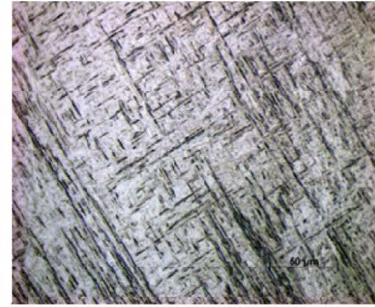

(b)

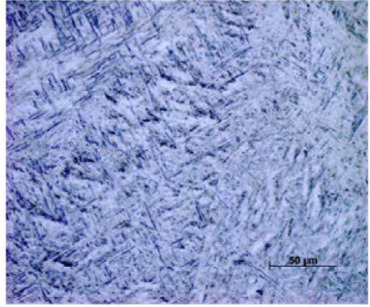

(c)

Figure 10. Comparison of optical non-data for HIP sample at 500× in the (a) XY, (b) XZ, and (c) YZ planes.

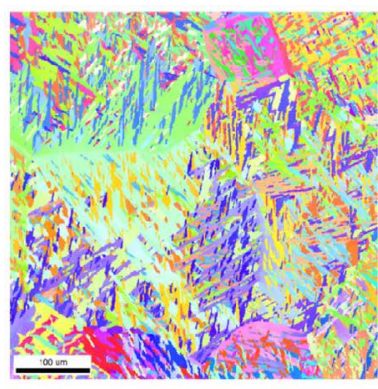

(a)

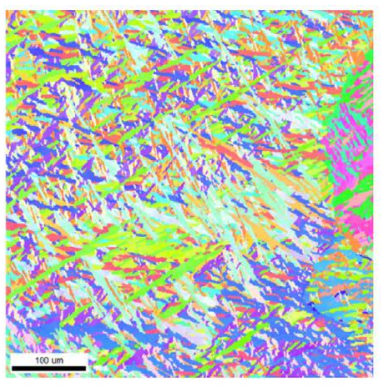

(b)

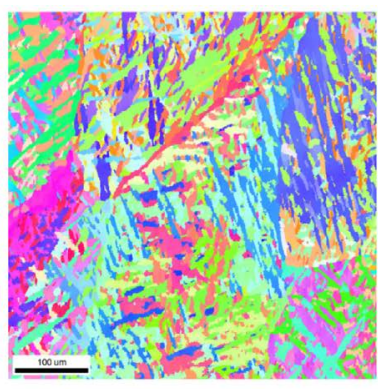

(c)

Figure 11. Comparison of EBSD data for HIP sample at 500 microns IPF in the (a) XY, (b) XZ, and (c) YZ planes.

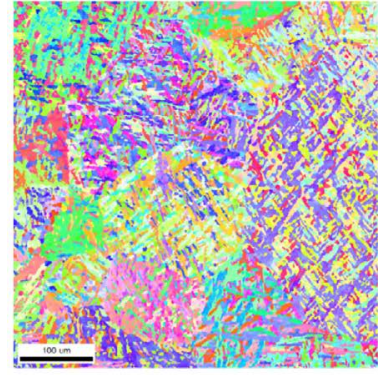

(a)

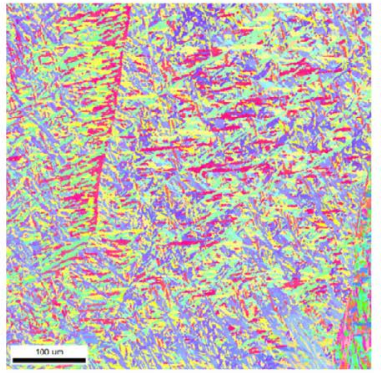

(b)

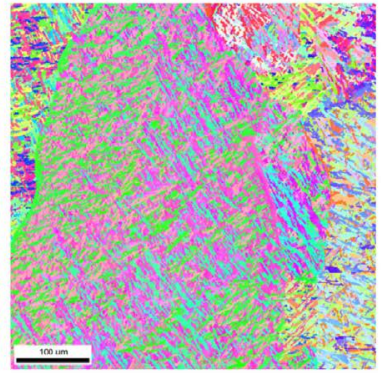

(c)

Figure 12.Comparison of EBSD data for non-HIP sample at 500 microns IPF in the (a) $\mathrm{XY}$, (b) XZ, and (c) YZ planes. 

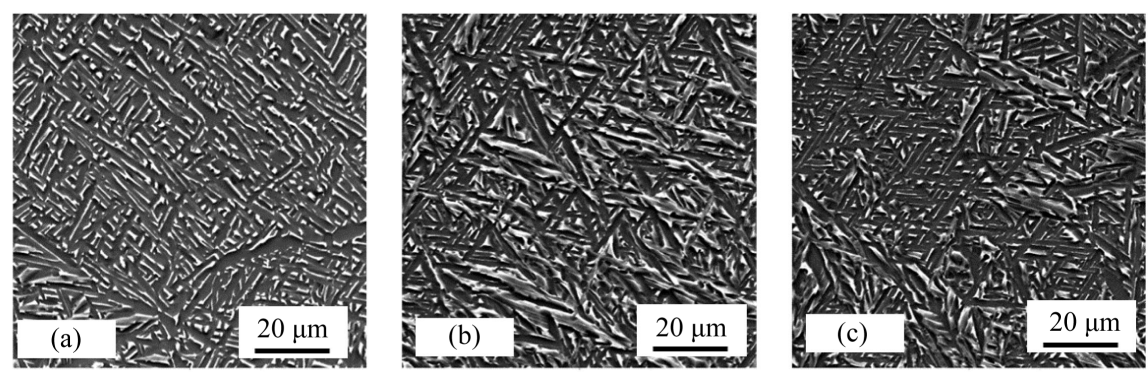

Figure 13. Comparison of SEM data for HIP sample in the (a) XY, (b) XZ, and (c) YZ planes.
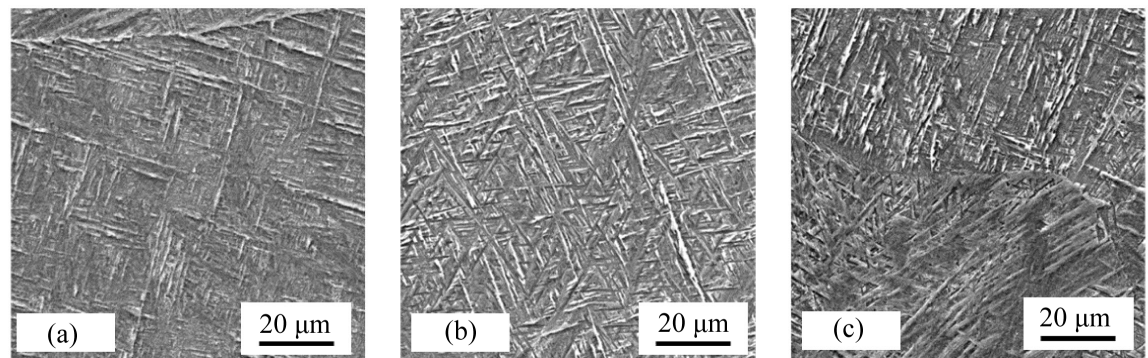

Figure 14. Comparison of SEM data for non-HIP sample in the (a) XY, (b) XZ, and (c) YZ planes.

Table 3. Properties of research titanium samples.

\begin{tabular}{cccccccc}
\hline & \multirow{2}{*}{ Wrought } & \multicolumn{3}{c}{ HIP } & \multicolumn{3}{c}{ Non-HIP } \\
\cline { 3 - 8 } & & $\mathrm{XY}$ & $\mathrm{XZ}$ & $\mathrm{YZ}$ & $\mathrm{XZ}$ & $\mathrm{XZ}$ & $\mathrm{YZ}$ \\
\hline Avg d1 $(\mu \mathrm{m})$ & 73.06 & 73.71 & 73.00 & 72.92 & 71.21 & 70.16 & 71.29 \\
Avg d2 $(\mu \mathrm{m})$ & 69.61 & 73.99 & 73.10 & 73.29 & 71351 & 71.11 & 71.26 \\
Avg hardness $(\mathrm{HV})$ & 363.02 & 339.27 & 347.62 & 347.13 & 364.53 & 371.73 & 365.12 \\
Avg grain size $(\mu \mathrm{m})$ & - & 13.00 & 14.00 & 23.00 & 10.8 & 9.20 & 9.70 \\
\hline
\end{tabular}

has no effect on the hardness of the sample. Hardness values are consistent with values from traditional manufacturing processes for $\alpha+\beta$ Ti64 as shown in Table 4 from [25].

\section{Discussion}

As expected, some grains undergo a phase transformation during the HIP process. These transformations show up at martensitic acicular structures inside of what appears to be a prior $\beta$ phase boundary [26]. Aluminum is an $\alpha$ stabilizer and is used to raise the $\beta$ transition temperature. Vanadium is a $\beta$ stabilizer and has the opposite effect. As a result, we see large patches of parallel plates of $\alpha$ grains surrounded by $\beta$ grain boundaries that have transformed into $\alpha$ grain upon cooling, see Figure 15. It should be noted that the basic microstructure is the same for both the HIP and non-HIP samples. Looking at the OP sample, Figure 16 shows the elongation of prior $\beta$ grains along the build direction. This is consistent with PBF AM Ti44 [27]. While some transitions occurred during 


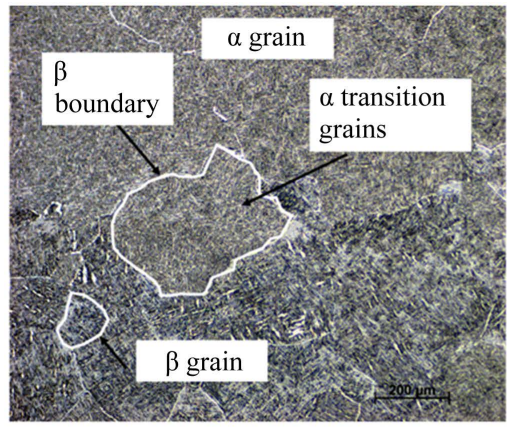

(a)

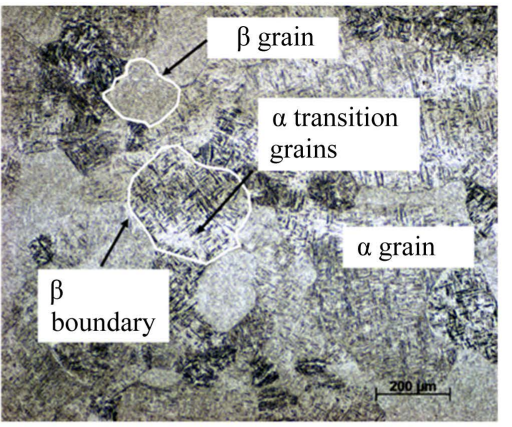

(b)

Figure 15. $\alpha$ and $\beta$ grain identification in the build plane at $100 \times$ in the (a) HIP and (b) non-HIP samples.

Table 4. Properties of various titanium alloys [25].

\begin{tabular}{|c|c|c|c|}
\hline Designation & $\begin{array}{c}\text { Yield } \\
\text { Strength } \\
(\mathrm{MPa})\end{array}$ & $\begin{array}{c}\text { Tensile } \\
\text { Strength } \\
(\mathrm{MPa})\end{array}$ & $\begin{array}{l}\text { Hardness } \\
\text { (Vickers) }\end{array}$ \\
\hline \multicolumn{4}{|l|}{ Unalloyed grades } \\
\hline Grade 1 (annealed) & 240 & 330 & 122 \\
\hline Grade 2 & $275-410$ & 344 & 145 \\
\hline Grade 3 (annealed) & 450 & 520 & 280 \\
\hline Grade 4 (annealed) & 590 & 660 & 280 \\
\hline Grade 7 (annealed) & 340 & 430 & 295 \\
\hline \multicolumn{4}{|l|}{$\alpha$ or near $\alpha$ alloys } \\
\hline Ti-3Al-2.5V ( $\alpha$ annealed) & 500 & 620 & 280 \\
\hline Ti-3Al-2.5V ( $\alpha-\beta$ annealed) & 530 & 620 & 300 \\
\hline Ti-3Al-2.5V ( $\beta$ annealed $)$ & 540 & 620 & 300 \\
\hline $\mathrm{Ti}-5 \mathrm{Al}-2.5 \mathrm{Sn}$ & 827 & 860 & 349 \\
\hline Ti-5Al-2.5Sn (ELI annealed) & 720 & 775 & 325 \\
\hline Ti-8Al-1Mo-1V & 910 & 937 & 349 \\
\hline \multicolumn{4}{|l|}{$\alpha+\beta$ alloys } \\
\hline Ti-6Al-4V (grade 5 annealed) & 880 & 950 & 349 \\
\hline Ti-6Al-4V (grade 5 ELI annealed) & 790 & 860 & 341 \\
\hline Ti-6Al-4V (grade 5 STA) & 1100 & 1170 & 396 \\
\hline Ti-6Al-6V-2Sn (annealed) & 980 & 1050 & 367 \\
\hline Ti-6Al-6V-2Sn (annealed) & 1035 & 1100 & 407 \\
\hline \multicolumn{4}{|l|}{$\mathrm{Ti}-6 \mathrm{Al}-6 \mathrm{~V}-2 \mathrm{Sn}\left(\operatorname{aged} 565^{\circ} \mathrm{C}\right)$} \\
\hline \multicolumn{4}{|l|}{$B$ alloys } \\
\hline Ti-15V-3Cr-3Al-3Sn (aged $\left.480^{\circ} \mathrm{C}\right)$ & 1250 & 1380 & 370 \\
\hline Ti-15V-3Cr-3Al-3Sn (aged $\left.545^{\circ} \mathrm{C}\right)$ & 1010 & 1110 & 410 \\
\hline
\end{tabular}




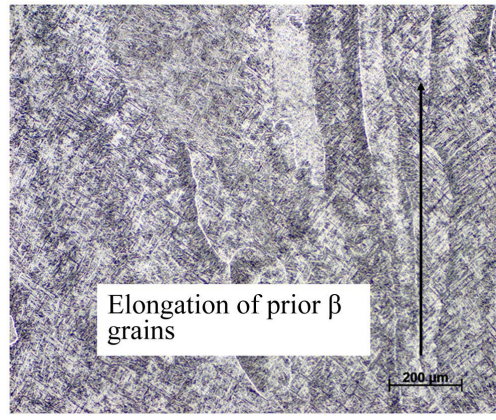

Figure 16. $\beta$ grain elongation in the build direction in the cross plane sample at $100 \times$.

the manufacturing process due to the thermal process of liquefying the powder bed and the subsequent rapid cooling to a solid part, we do see additional transformations in the HIP samples. PBF manufactured Ti64 tends to have a coarsening of the microstructure and an enlargement in the grain size as shown in Table 3 [28]. This results in a decrease in the hardness value as expected [29]. The increase in grain size results in a reduction in the grain boundary area. This also follows with a Hall-Petch relationships between hardness and grain size and is consistent with other research involving hardness, grain size, and AM Ti64 [30]. Figure 15 also shows a finer $\alpha / \alpha$ phase in the HIP sample, indicating possible decomposition of the acicular martensite. This would cause some stress relief in the sample and lead to the lower hardness value recorded in Table 3 [31]. Figure 17 shows the basket-weave like pattern of Widmanstatten microstructure. This lamellar microstructure is formed when materials are cooled at a critical rate from extremely high temperatures [32].

Wrought samples are characterized by equiaxed $\alpha$ phase surrounded by $\beta$ phase as shown in Figure 18. This should lead to a greater hardness value when compared to the AM samples. However, it is comparable with the values from the non-HIP samples. The similarity in metallurgical properties between the wrought samples and the non-HIP samples is consistent with PBF AM Ti64 [33]. This could be attributed to the increase in the number of grain boundaries and martensitic acicular structures. The consistency in the hardness values is a further indication of a lack of voids in the AM samples. Figure 19 and Figure 20 confirm the globular microstructure.

Although the compositional makeup of the samples is identical, the different manufacturing processes produced different microstructures. Figure 21 highlights these differences. The wrought samples are made up of a combination of equiaxed $\alpha$ with bi-modal microstructures of $\alpha+\beta$ plates. This is contrasted by the AM sample showing the previously describes acicular $\alpha$ grains within the prior $\beta$ grain boundaries. The microstructure is a result of the manufacturing process. For the AM part, SLM causes liquefaction of the alloy powder. The drives the temperature of the sample well above the $\beta$ transition temperature. The subsequent rapid cooling and solidification of the material causes the $\alpha$ martensitic structures to form [24]. Both the build and orthogonal planes exhibit these microstructures. 


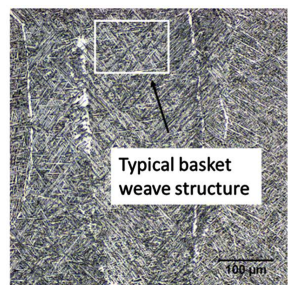

(a)

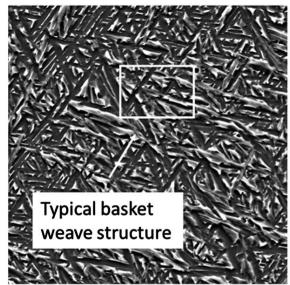

(b)

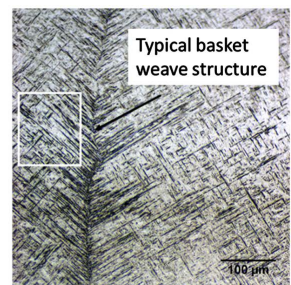

(c)

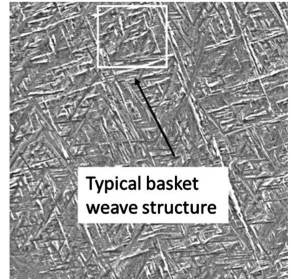

(d)

Figure 17. Microstructure identification in the orthogonal plane at $200 \times$ optical and SE 100 SEM in the (a), (b) HIP and (c), (d) non-HIP samples.

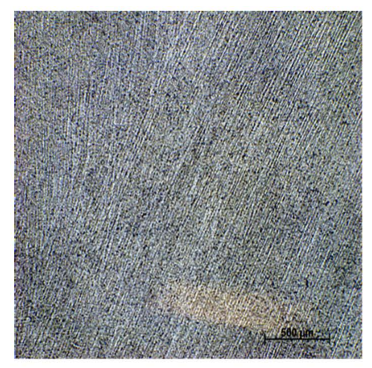

(a)

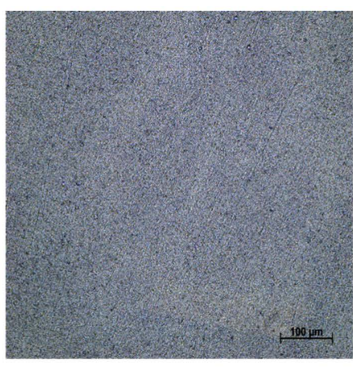

(b)

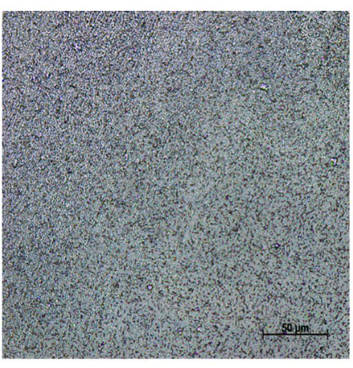

(c)

Figure 18. Comparison of optical data for wrought samples at (a) $50 \times$, (b) $200 \times$, and (c) $500 \times$.

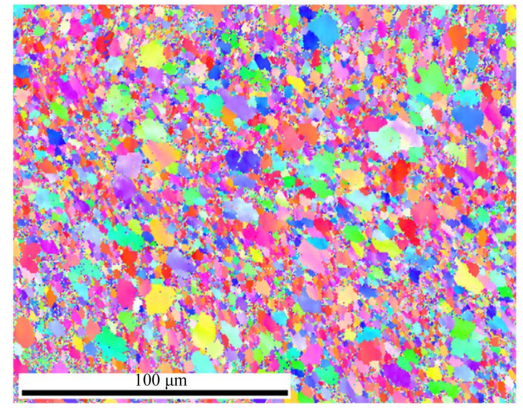

Figure 19. EBSD Data for wrought sample at 500 microns IPF.

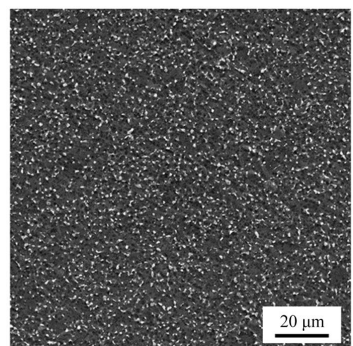

Figure 20. SEM image for wrought sample. 


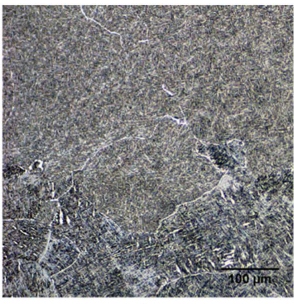

(a)

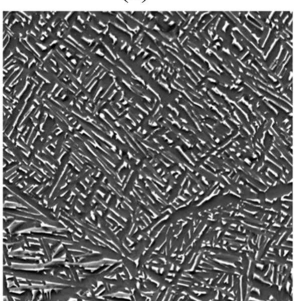

(c)

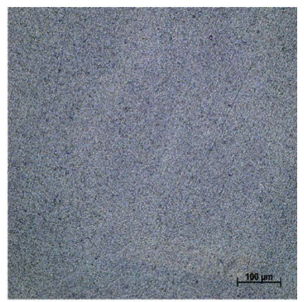

(b)

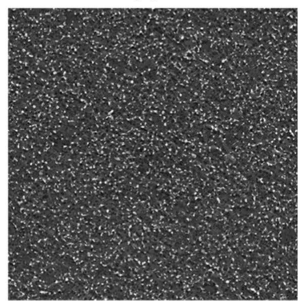

(d)

Figure 21. A comparison of optical and SEM data in the build plane for ((a), (c)) AM Ti64 and ((b), (d)) wrought samples.

\section{Conclusion}

This paper compared HIP and non-HIP samples of SLS Ti64 to traditionally manufactured wrought T-64. Several conclusions were made during the final analysis. There is clear difference in grain orientation between the build plane and the orthogonal planes and this anisotropy continues through post processing by HIP; however, this difference in grain structure had minimal difference in hardness of the alloy in the opposing planes. Elemental distribution and chemical composition of the AM sample are similar to wrought Ti64. There is a clear difference in grain structure between AM Ti64 and wrought Ti64.

\section{Conflicts of Interest}

The authors declare no conflicts of interest regarding the publication of this paper.

\section{References}

[1] Gustavo, T. and Elwany, A. (2014) A Review on Process Monitoring and Control in Metal-Based Additive Manufacturing. Journal of Manufacturing Science and Engineering, 136, Article ID: 060801. https://doi.org/10.1115/1.4028540

[2] Thompson, M.K., Moroni, G., Vaneker, T., Fadel, G., Campbell, R.I., Gibson, I., Bernard, A., et al. (2016) Design for Additive Manufacturing: Trends, Opportunities, Considerations and Constraints. CIRP Annals-Manufacturing Technology, 65, 737-760. https://doi.org/10.1016/j.cirp.2016.05.004

[3] Xu, W., Sun Brandt, S., Elambasseril, J., Liu, Q., Latham, K., Xia, K. and Qian, M. (2015) Additive Manufacturing of Strong and Ductile Ti-6Al-4V by Selective Laser Melting via in Situ Martensite Decomposition. Acta Materialia, 85, 74-84. https://doi.org/10.1016/j.actamat.2014.11.028

[4] Wong, K.V. and Hernandez, A. (2012) A Review of Additive Manufacturing. International Scholarly Research Notices, 2012, Article ID: 208760. https://doi.org/10.5402/2012/208760 
[5] Jared, B.H., Aguilo, M.A., Beghini, L.L., Boyce, B.L., Clark, B.W., Cook, A., Kaehr, B.J. and Robbins, J. (2017) Additive Manufacturing: Towards Holistic Design. Scripta Materialia, 135, 141-147. https://doi.org/10.1016/j.scriptamat.2017.02.029

[6] Iso, A. (2015) ASTM52900-15 Standard Terminology for Additive ManufacturingGeneral Principles-Terminology. American Society for Testing and Materials, West Conshohocken.

[7] Deckers, J., Vleugels, J. and Kruth, J.-P. (2014) Additive Manufacturing of Ceramics: A Review. Journal of Ceramic Science and Technology, 5, 245-260.

[8] Turner, B.N., Strong, R. and Gold, S.A. (2014) A Review of Melt Extrusion Additive Manufacturing Processes: I. Process Design and Modeling. Rapid Prototyping Journal, 20, 192-204. https://doi.org/10.1108/RPJ-01-2013-0012

[9] Yap, Y.L., Wang, C., Sing, S.L., Dikshit, V., Yeong, W.Y. and Wei, J. (2017) Material Jetting Additive Manufacturing: An Experimental Study Using Designed Metrological Benchmarks. Precision Engineering, 50, 275-285.

https://doi.org/10.1016/j.precisioneng.2017.05.015

[10] Meteyer, S., Xu, X., Perry, N. and Zhao, F.Y. (2014) Energy and Material Flow Analysis of Binder Jetting Additive Manufacturing Processes. Procedia CIRP, 15, 19-25. https://doi.org/10.1016/j.procir.2014.06.030

[11] Carroll, B.E., Palmer, T.A. and Beese, A.M. (2015) Anisotropic Tensile Behavior of Ti-6Al-4V Components Fabricated with Directed Energy Deposition Additive Manufacturing. Acta Materialia, 87, 309-320. https://doi.org/10.1016/j.actamat.2014.12.054

[12] King, W.E., Anderson, A., Ferencz, R., Hodge, N., Kamath, C., Khairallah, S. and Rubencik, A.M. (2015) Laser Powder Bed Fusion Additive Manufacturing of Metals: Physics, Computational, and Materials Challenges. Applied Physics Reviews, 2, Article ID: 041304. https://doi.org/10.1063/1.4937809

[13] Vrancken, B., Thijs, L., Kruth, J.-P. and Van Humbeeck, J. (2012) Heat Treatment of Ti6Al4V Produce by Selective Laser Melting: Microstructure and Mechanical Properties. Journal of Alloys and Compounds, 541, 177-185. https://doi.org/10.1016/j.jallcom.2012.07.022

[14] Kumar, S. (2003) Selective Laser Sintering: A Qualitative and Objective Approach. JOM, 55, 43-47. https://doi.org/10.1007/s11837-003-0175-y

[15] Hack, H., Richard, L., Erik, K., Brad, B. and Scott, O. (2017) Mechanical Properties of Additive Manufactured Nickel Alloy 625. Additive Manufacturing, 14, 105-115. https://doi.org/10.1016/j.addma.2017.02.004

[16] de Formanoir, C., Michotte, S., Rigo, O., Germain, L. and Godet, S. (2016) Electron Beam Melted Ti-6Al-4V: Microstructure, Texture and Mechanical Behavior of the As-Built and Heat-Treated Material. Materials Science and Engineering: A, 652, 105-119. https://doi.org/10.1016/j.msea.2015.11.052

[17] Atkinson, H.V. and Davies, S. (2000) Fundamental Aspects of Hot Isostatic Pressing: An Overview. Metallurgical and Materials Transactions A, 31, 2981-3000. https://doi.org/10.1007/s11661-000-0078-2

[18] Tong, J., Bowen, C.R., Persson, J. and Plummer, A. (2017) Mechanical Properties of Titanium-Based Ti-6Al-4V Alloys Manufactured by Powder Bed Additive Manufacture. Materials Science and Technology, 33, 138-148. https://doi.org/10.1080/02670836.2016.1172787

[19] Pederson, R. (2002) Microstructure and Phase Transformation of Ti-6Al-4V. Licentiate Thesis, Lulea University of Technology, Luleå. 
[20] Kao, Y.L., Tu, G.C., Huang, C.A. and Liu, T.T. (2005) A Study on the Hardness of aand b-Pure Titanium with Different Grain Sizes. Materials Science and Engineering: A, 398, 93-98. https://doi.org/10.1016/j.msea.2005.03.004

[21] Sidambe, A.T. (2014) Biocompatibility of Advance Manufactured Titanium Implants: A Review. Materials, 7, 8168-8188. https://doi.org/10.3390/ma7128168

[22] Wright, S.I., Nowell, M.M., de Kloe, R., Camus, P. and Rampton, T. (2015) Electron Imaging with an EBSD Detector. Ultramicroscopy, 148, 132-145. https://doi.org/10.1016/j.ultramic.2014.10.002

[23] Liu, S. and Shin, Y.C. (2018) Additive Manufacturing of Ti6Al4V Alloy: A Review. Materials and Design, 164, Article ID: 107552.

https://doi.org/10.1016/j.matdes.2018.107552

[24] Wysocki, B., Maj, P., Sitek, R., Buhagiar, J., Kurzydlowski, K.J. and Swieszkowski, W. (2017) Laser and Electron Beam Additive Manufacturing Methods of Fabricating Titanium Bone Implants. Applied Sciences, 7, Article No. 657. https://doi.org/10.3390/app7070657

[25] Boyer, R., Collings, E.W. and Welsch, G. (1994) Material Properties Handbook: Titanium Alloys. ASM International, Almere.

[26] Rafi, H.K., Karthik, N.V., Gong, H., Starr, T.L. and Stucker, B.E. (2013) Microstructures and Mechanical Properties of Ti6Al4V Parts Fabricated by Selective Laser Melting and Electron Beam Melting. Journal of Materials Engineering and Performance, 22, 3872-3883. https://doi.org/10.1007/s11665-013-0658-0

[27] Antonysamy, A.A., Meyer, J. and Prangnell, P.B. (2013) Effect of Build Geometry on the $\beta$-Grain Structure and Texture in Additive Manufacturing of Ti-6Al-4V by Selective Electron Beam Melting. Materials Characterization, 84, 153-168. https://doi.org/10.1016/j.matchar.2013.07.012

[28] Al-Bermani, S., Blackmore, M., Zhang, W. and Todd, I. (2010) The Origin of Microstructural Diversity, Texture, and Mechanical Properties in Electron Beam Melted Ti6Al4V. Metallurgical and Materials Transactions A, 41, 3422-3434. https://doi.org/10.1007/s11661-010-0397-x

[29] Jiang, C.-P. and Huang, Z.-H. (2014) Grain Size Effect on Mechanical Properties of Titanium Alloy. Key Engineering Materials, 626, 548-552. https://doi.org/10.4028/www.scientific.net/KEM.626.548

[30] Mitzner, S., Liu, S., Domack, M. and Hafley, R. (2012) Grain Refinement of Freeform Fabricated Ti-6Al-4V Alloy Using Beam/ARC Modulation. 23rd Annual International Solid Freeform Fabrication Symposium-An Additive Manufacturing Conference, Austin, 6-8 August 2012, 536-555.

[31] He, J., Li, D., Jiang, W., Ke, L., Qin, G., Ye, Y., Qin, Q. and Qiu, D. (2019) The Martensitic Transformation and Mechanical Properties of Ti6Al4V Prepared via Selective Laser Melting. Materials, 12, Article No. 321.

https://doi.org/10.3390/ma12020321

[32] Fan, Y., Tian, W., Guo, Y., Sub, A. and Xu, J. (2016) Relationships among Microstructure, Mechanical Properties, and Fatigue Behavior in Thin Ti6Al4V. Advances in Materials Science and Engineering, 2016, Article ID: 7278267.

https://doi.org/10.1155/2016/7278267

[33] Murr, L.E. (2015) Metallurgy of Additive Manufacturing: Examples from Electron Beam Melting. Additive Manufacturing, 5, 40-53.

https://doi.org/10.1016/j.addma.2014.12.002 